\title{
Efficacy of Cetylpyridinium Chloride against Listeria monocytogenes and Its Influence on Color and Texture of Cooked Roast Beef ${ }^{\dagger}$
}

\author{
M. SINGH, H. THIPPAREDDI, $;$ R. K. PHEBUS,* J. L. MARSDEN, T. J. HERALD, AND A. L. NUTSCH \\ Department of Animal Sciences \& Industry and Food Science Institute, Kansas State University, Manhattan, Kansas 66506, USA
}

MS 05-56: Received 15 February 2005/Accepted 26 May 2005

\begin{abstract}
Sliced (cut) and exterior (intact) surfaces of restructured cooked roast beef were inoculated with Listeria monocytogenes, treated with cetylpyridinium chloride (CPC; immersion in $500 \mathrm{ml}$ of $1 \%$ solution for $1 \mathrm{~min}$ ), individually vacuum packaged, and stored for 42 days at 0 or $4^{\circ} \mathrm{C}$. Noninoculated samples were similarly treated, packaged, and stored to determine effects on quality (color and firmness) and on naturally occurring bacterial populations, including aerobic plate counts and lactic acid bacteria. Immediately after CPC treatment, regardless of inoculation level, $L$. monocytogenes populations were reduced $(P=$ 0.05 ) by about $2 \log \mathrm{CFU} / \mathrm{cm}^{2}$ on sliced surfaces and by about $4 \log \mathrm{CFU} / \mathrm{cm}^{2}$ on exterior surfaces. Throughout 42 days of refrigerated storage (at both 0 and $\left.4^{\circ} \mathrm{C}\right), L$. monocytogenes populations on CPC-treated samples remained lower $(P=0.05)$ than those of nontreated samples for both surface types. After 42 days of storage at both 0 and $4^{\circ} \mathrm{C}$, aerobic plate count and lactic acid bacteria populations of treated samples were 1 to $1.5 \log \mathrm{CFU} / \mathrm{cm}^{2}$ lower $(P=0.05)$ than those of nontreated samples for both surface types. CPC treatment resulted in negligible effects $(P>0.05)$ on the color $\left(\mathrm{L}^{*}, \mathrm{a}^{*}\right.$, and $\mathrm{b}^{*}$ values) of exterior and sliced roast beef surfaces during storage. For both sliced and exterior surfaces, CPC-treated samples were generally less firm than nontreated samples. CPC treatment effectively reduced $L$. monocytogenes populations on roast beef surfaces and resulted in relatively minor impacts on color and texture attributes. CPC treatment, especially when applied to products prior to slicing, may serve as an effective antimicrobial intervention for ready-to-eat meat products.
\end{abstract}

Listeria monocytogenes is a foodborne pathogen of significant public health concern because of its virulence in susceptible individuals. Most cases of human listeriosis appear to be sporadic, and the source and route of infection are usually unknown. However, the association of L. monocytogenes with several large foodborne outbreaks suggests that contaminated food is the primary source of the organism, with ready-to-eat (RTE) meat products among the foods most commonly associated with food-related listeriosis (17). In the recent past, various multistate outbreaks of listeriosis that are associated with RTE meats have occurred in the United States. For example, in 2002, an outbreak of L. monocytogenes infection with 46 culture-confirmed cases, 7 deaths, and 3 stillbirths or miscarriages in eight states was linked to turkey deli meat (5). This outbreak led to a recall involving 12.4 million $\mathrm{kg}$ of fresh and frozen RTE turkey and chicken products.

The U.S. Department of Agriculture Food Safety and Inspection Service (USDA-FSIS) classifies deli-type products that are either sliced in the establishment or likely to be sliced at retail, such as cured hams, roast beef or turkey, bologna, luncheon meat, pastrami, and other cold cuts, as

\footnotetext{
* Author for correspondence. Tel: 785-532-1215; Fax: 785-532-5681; E-mail: phebus@ksu.edu.

$\dagger$ Contribution 05-135-J from the Kansas Agricultural Experiment Station, Manhattan, Kans.

\$ Present address: Department of Food Science and Technology, University of Nebraska, Lincoln, NE 68583, USA.
}

high-risk products relative to $L$. monocytogenes contamination (18). As reported by Zaika et al. (24), $26 \%$ of frozen minced beef steak samples, $22 \%$ of RTE delicatessen products, and $10 \%$ of delicatessen products to be consumed after cooking were positive for $L$. monocytogenes. Despite a declining prevalence of L. monocytogenes in RTE meat and poultry products sampled for regulatory purposes (9) and decreases in the annual incidence of listeriosis by $44 \%$ between 1989 and 1993 and by 38\% between 1996 and 2002 (6), additional improvements in the microbiological safety of these products are warranted. The presence of $L$. monocytogenes in processed meats at high frequency, the ubiquitous presence of this pathogen in processing plant environments, and the high rate of asymptomatic human carriers (8) suggest that the key issue with the safety of cooked RTE meat and poultry products is postprocess recontamination, mainly during peeling, slicing, and packaging.

Researchers have evaluated various means of improving the safety of deli-type RTE meat products, including antimicrobial packaging films $(4,10)$, application of antimicrobial treatments such as organic acids $(12,13)$ and nisin (12) prior to final packaging, and postpackage pasteurization technologies such as high-pressure (1) and thermal treatments $(10,11)$. Recent USDA-FSIS regulations require processors to incorporate strategies to control L. monocytogenes in postlethality exposed RTE meat products by one of three defined alternatives, with preferred tactics including postlethality treatments (e.g., steam pasteurization, hot 
water pasteurization, radiant heating, high-pressure processing) and antimicrobials or growth inhibitors (19). Thus, there is a need for research to evaluate and validate additional postlethality treatments and antimicrobial agents and processes.

Cetylpyridinium chloride (CPC), a quaternary ammonium compound, has been approved for application to raw poultry products by the USDA and the U.S. Food and Drug Administration $(16,20)$ and is the active ingredient in some mouthwashes (2). CPC has been applied as a dip or spray to a variety of food matrices, including poultry skin $(2,3$, 22,23 ), fresh beef tissue (7), and fresh-cut vegetables (21), with demonstrated effectiveness against pathogens such as Escherichia coli 0157:H7, Salmonella spp., and Listeria spp. The objectives of this study were to examine the efficacy of CPC as a postprocess decontaminant for exterior and sliced roast beef surfaces prior to packaging and to determine the influence of CPC treatment on quality attributes (color and firmness) after extended chilled storage.

\section{MATERIALS AND METHODS}

Preparation of bacterial cultures. A five-strain cocktail of L. monocytogenes (serotype 3 [ATCC 19113]; serotype 4c [ATCC 19116]; and strains 101M, 109, and 108M obtained from Dr. Larry Beuchat, University of Georgia) was used to inoculate roast beef. Cultures were maintained separately at $4^{\circ} \mathrm{C}$ on tryptic soy agar slants (TSA; Difco, Becton Dickinson, Sparks, Md.). Cultures were transferred every 30 days to maintain viability. The inoculum was prepared by transferring cultures individually into $10 \mathrm{ml}$ of tryptic soy broth (TSB; Difco, Becton Dickinson) and incubating at $35^{\circ} \mathrm{C}$ for $24 \mathrm{~h}$. Aliquots $(1 \mathrm{ml})$ of each were then transferred individually into $100 \mathrm{ml}$ of TSB contained in 250-ml centrifuge bottles and further incubated at $35^{\circ} \mathrm{C}$ for $20 \mathrm{~h}$. The resultant cultures were centrifuged at $15,600 \times g$ for $10 \mathrm{~min}$ at $4^{\circ} \mathrm{C}$. The supernatant was removed, and the cell pellets were resuspended in $50 \mathrm{ml}$ of $0.1 \%$ sterile peptone water (Difco, Becton Dickinson) and recentrifuged. The supernatant was removed, and the resultant pellets were resuspended in $10 \mathrm{ml}$ of peptone water. A cocktail was prepared by mixing the five cultures in a sterile bottle to achieve a final volume of $50 \mathrm{ml}$ of the combined inoculum; cell density was determined by plating on modified Oxford agar (Oxoid Ltd., Basingstoke, Hampshire, UK). This mixed culture was deemed the high-level inoculum; to prepare the low-level inoculum, a portion of the original cocktail was diluted by a factor of 10,000. The high- and low-inoculum suspensions were each placed in high-density polyethylene plastic spray bottles (Sprayco, Detroit, Mich.) for use in the mist inoculation procedure.

Preparation and inoculation of roast beef samples. Restructured cooked roast beef chubs (51 cm long) were obtained from a commercial manufacturer and stored at $0^{\circ} \mathrm{C}$ prior to use. For these studies, the vacuum-packaged roast beef product was removed from storage, the packaging was aseptically removed, and the slices ( $15 \mathrm{~cm}$ long, $10 \mathrm{~cm}$ wide, $5 \mathrm{~cm}$ thick) were prepared, with each slice having a "sliced/cut" surface and an "exterior" surface (original surface in contact with the casing during cooking operations). Slices were inoculated to determine the efficacy of CPC against L. monocytogenes populations; noninoculated slices were used to evaluate the efficacy of CPC against naturally occurring bacterial populations and to determine quality effects (color and firmness). Slices to be inoculated were individually placed on a tray, misted with inoculum in a biocontaminant chamber, and held for $30 \mathrm{~min}$ in a sterile laminar flow cabinet to allow surface attachment of L. monocytogenes. Samples were inoculated at either a high ( 7 to $8 \log \mathrm{CFU} / \mathrm{cm}^{2}$ ) or a low (3 to 4 $\left.\log \mathrm{CFU} / \mathrm{cm}^{2}\right)$ initial level.

CPC treatment and sample storage. A $1 \%$ solution of CPC (CECURE, Safe Foods Corporation, North Little Rock, Ark.) was prepared by adding $25 \mathrm{ml}$ of $40 \%$ concentrated CPC to $1,000 \mathrm{ml}$ of $25^{\circ} \mathrm{C}$ deionized water. Individual slices (both inoculated and noninoculated) of roast beef were immersed in $500 \mathrm{ml}$ of CPC solution $\left(25^{\circ} \mathrm{C}\right)$ for $1 \mathrm{~min}$. Individual slices were then vacuum packaged in cryovac bags (Cryovac Sealed Air Corporation, Duncan, S.C.; oxygen transmission $=3$ to $6 \mathrm{cc} / \mathrm{m}^{2} / 24 \mathrm{~h}$ at $1 \mathrm{~atm}$, $4.4^{\circ} \mathrm{C}$, and $0 \%$ relative humidity; water vapor transmission, 0.5 to $0.6 \mathrm{~g} / 645 \mathrm{~cm}^{2} / 24 \mathrm{~h}, 100 \%$ relative humidity) and stored at either $0^{\circ} \mathrm{C}$ (dark conditions) or $4^{\circ} \mathrm{C}$ (lighted) for 42 days. Each CPCtreated sample had a corresponding control (nontreated) sample that was identically stored and analyzed. Samples stored at $4{ }^{\circ} \mathrm{C}$ were held in a display case with lighting conditions simulating those of retail stores. The light intensity was maintained at 1,070 lux (107-ft candles) using deluxe warm-white fluorescent light and was measured at weekly intervals with a light meter (model 407026, Extech Instruments Corp., Waltham, Mass.). Packages were rotated at 3-day intervals for even distribution of light on the sample surfaces.

Sample collection and microbiological analysis. Samples were analyzed on days $0,3,7,14,21,28$, and 42 of storage. Inoculated samples were analyzed for L. monocytogenes populations; noninoculated samples were analyzed for total aerobic plate counts (APCs), E. coli, total coliform, lactic acid bacteria (LAB), and yeast and mold populations.

Two cores (each $3.4 \mathrm{~cm}$ in diameter and $0.5 \mathrm{~cm}$ thick) were excised from both the exterior surface and the sliced surface of roast beef slices, and the tissue from each surface was analyzed separately. The cores were homogenized with $25 \mathrm{ml}$ of $0.1 \%$ sterile peptone water in a stomacher 400 lab blender for $2 \mathrm{~min}$; serial dilutions were then prepared in sterile peptone water.

L. monocytogenes populations were determined quantitatively by plating appropriate dilutions on modified Oxford agar and tryptose phosphate agar (Difco, Becton Dickinson) using a Whitley automatic spiral plater (Don Whitley Scientific Ltd., Shipley, West Yorkshire, UK). After incubation at $35^{\circ} \mathrm{C}$ for 24 to $48 \mathrm{~h}$, CFUs typical of L. monocytogenes were enumerated. Five typical colonies from duplicate plates of modified Oxford agar and tryptose phosphate agar were confirmed as L. monocytogenes by Gram staining procedures and a catalase test. Further verification was performed by performing a fermentation of glucose, xylose, and mannitol and a reduction of nitrite.

Appropriate serial dilutions of noninoculated samples were analyzed using APC Petrifilm (3M Corp., St. Paul, Minn.) to determine APCs and E. coli Count Petrifilm (3M) to determine $E$. coli and total coliform populations. APC and E. coli Count Petrifilm were incubated at $35^{\circ} \mathrm{C}$ for 24 to $48 \mathrm{~h}$. Potato dextrose agar (Difco, Becton Dickinson) incubated at $25^{\circ} \mathrm{C}$ for $48 \mathrm{~h}$ was used to estimate yeast and mold populations. $\mathrm{LAB}$ populations were determined using deMan Rogosa Sharpe agar (Difco, Becton Dickinson) incubated anaerobically at $35^{\circ} \mathrm{C}$ for 24 to $48 \mathrm{~h}$ in anaerobe jars with anaerobic system envelopes (GasPak Plus, Becton Dickinson Microbiology Systems, Sparks, Md.).

Quality attributes (color and firmness) of roast beef. Noninoculated samples were used to evaluate the effects of CPC treatment on surface color and firmness of roast beef. Color was evaluated separately on both the exterior and the sliced surfaces. A 

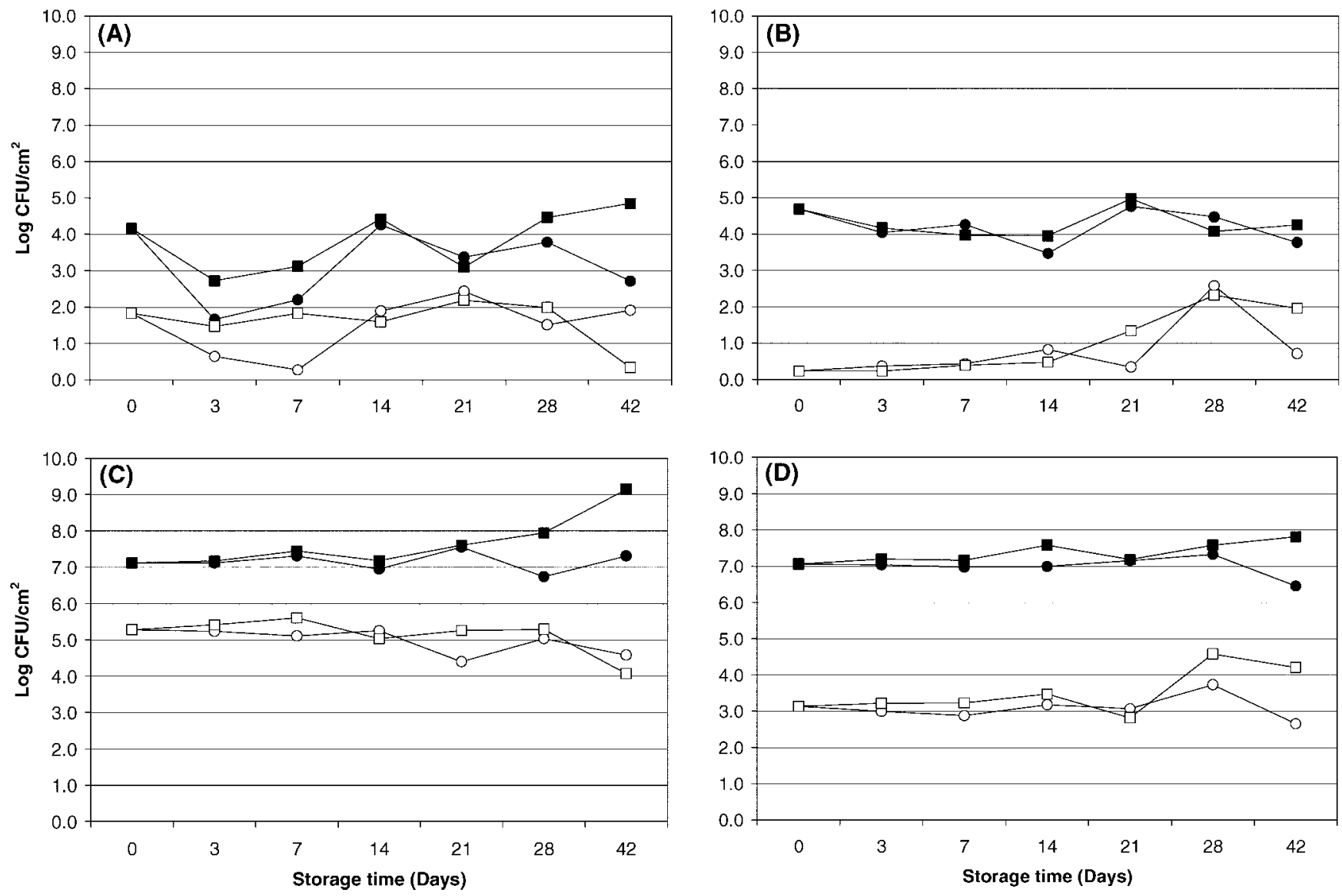

FIGURE 1. L. monocytogenes populations on sliced or exterior roast beef surfaces inoculated at low $\left(\mathrm{ca} .4 \mathrm{log} C \mathrm{CH} / \mathrm{cm}{ }^{2}\right) \mathrm{or}$ high $(\mathrm{ca}$. $7 \log C F U / \mathrm{cm}^{2}$ ) initial levels and either not treated (control) or treated with cetylpyridinium chloride (immersion in $1 \%$ solution for 1 min) and stored vacuum packaged for 42 days at 0 or $4^{\circ} \mathrm{C}$. (A) Sliced surfaces, low inoculation; (B) exterior surfaces, low inoculation; (C) sliced surfaces, high inoculation; and (D) exterior surfaces, high inoculation. $\bigcirc$, Ctrl $0^{\circ} \mathrm{C} ; \square, \mathrm{Ctrl} 4^{\circ} \mathrm{C} ; \mathrm{O}, \mathrm{Trt} \mathrm{O}^{\circ} \mathrm{C} ; \square, \mathrm{Trt} 4{ }^{\circ} \mathrm{C}$.

Hunter Miniscan spectrophotometer (model MS/S-4000S, Hunter Associated Lab., Inc., Reston, Va.) was used to determine the lightness ( $\mathrm{L}^{*}$ values), redness (a* values), and yellowness ( $\mathrm{b}^{*}$ values) of roast beef samples. For cut surfaces, the average of four readings (two from each cut side) was used for analysis, whereas for the exterior surface, two readings from the exterior surface were used for analysis.

A texture analyzer (TA-XT2, Stable Micro Systems, Haslemere, UK) was used to determine the firmness of roast beef samples. A p/0.5S stainless steel spherical 1.27-cm-diameter ball probe with $100 \mathrm{~g}$ of force and $1.7 \mathrm{~mm} / \mathrm{s}$ test speed penetrating $8.9 \mathrm{~mm}$ into the surface of the product was used. Samples were removed from 0 and $4{ }^{\circ} \mathrm{C}$ storage and tempered at room temperature for $30 \mathrm{~min}$ prior to analysis. The firmness of exterior and sliced surfaces was evaluated separately using intact slices.

Experimental design and statistical analysis. All microbial populations were reported as log CFU per square centimeter. A completely randomized block design was used to evaluate microbial populations as well as the color and firmness of the roast beef stored at 0 and $4^{\circ} \mathrm{C}$ with repeated measures on days $0,3,7,14$, 21, 28, and 42. Three replications of this experiment were performed. Analysis of variance was performed using the SAS PROC MIXED procedure and a comparison of the LSmeans.

\section{RESULTS AND DISCUSSION}

Effect of $1 \%$ CPC treatment on $L$. monocytogenes populations. Analysis of variance of L. monocytogenes populations recovered from the exterior and the sliced surfaces of roast beef samples inoculated at low initial levels $\left(4 \log \mathrm{CFU} / \mathrm{cm}^{2}\right)$ after treatment with $1 \% \mathrm{CPC}$ and storage for 42 days at 0 and $4^{\circ} \mathrm{C}$ indicated significant $(P=0.05)$ interactive effects of storage temperature, storage days, and $1 \%$ CPC treatment. In addition to this interactive effect, the individual main effects of storage temperature, storage time, and $1 \%$ CPC treatment significantly $(P=0.05)$ affected the growth of $L$. monocytogenes on both exterior and sliced roast beef surfaces.

Figure 1A shows the L. monocytogenes populations on the sliced surface inoculated at low initial levels for both control (nontreated) and CPC-treated samples during 42 days of storage at 0 and $4^{\circ} \mathrm{C}$. CPC treatment of the sliced roast beef surface had an immediate bactericidal effect on L. monocytogenes (reduced initial populations by about 2 $\log \mathrm{CFU} / \mathrm{cm}^{2}$ ) and exhibited a bacteriostatic effect during the 42-day storage period (Fig. 1A).

L. monocytogenes populations of exterior roast beef surfaces inoculated at low initial levels (ca. $4 \log \mathrm{CFU} / \mathrm{cm}^{2}$ ) are shown in Figure 1B. CPC treatment clearly demonstrated a listericidal activity on exterior roast beef surfaces immediately after application, reducing $L$. monocytogenes populations by $>4 \log \mathrm{CFU} / \mathrm{cm}^{2}$. Thereafter, populations remained relatively constant at $<1 \log \mathrm{CFU} / \mathrm{cm}^{2}$; toward 
the end of storage (days 21 to 42), L. monocytogenes populations on treated samples increased by ca. 2 log cycles. Listeria populations on nontreated exterior surfaces remained within the range of the original inoculation level (about 4 to $5 \log \mathrm{CFU} / \mathrm{cm}^{2}$ ) throughout storage. Populations on CPC-treated exterior surfaces were 2 to 4 log cycles $\mathrm{CFU} / \mathrm{cm}^{2}$ lower than on nontreated products.

For sliced roast beef surfaces inoculated at high initial levels (Fig. 1C), CPC-treated samples had significantly ( $P$ $=0.05$ ) lower L. monocytogenes populations than nontreated samples at both storage temperatures. Furthermore, for the control samples of this group, substantially higher $(P$ $=0.05)$ L. monocytogenes populations were observed on samples stored at $4^{\circ} \mathrm{C}$ than at $0^{\circ} \mathrm{C}$ on days 28 and 42 (Fig. $1 \mathrm{C})$. For this product surface type, $1 \% \mathrm{CPC}$ seemed to provide a bacteriostatic effect, particularly at the $4^{\circ} \mathrm{C}$ storage temperature.

A significant $(P=0.05)$ bactericidal effect was observed immediately after CPC treatment on exterior roast beef surfaces inoculated at high initial levels (Fig. 1D), as L. monocytogenes populations were reduced by $4 \mathrm{log} \mathrm{CFU} /$ $\mathrm{cm}^{2}$. L. monocytogenes populations on treated samples remained about $4 \log \mathrm{CFU} / \mathrm{cm}^{2}$ lower $(P=0.05)$ than those on nontreated samples through day 21 of storage. At the end of storage, populations on treated samples remained significantly $(P=0.05)$ lower than those on nontreated samples and, within treatment, samples stored at $0^{\circ} \mathrm{C}$ demonstrated somewhat lower populations than samples stored at $4^{\circ} \mathrm{C}$ (Fig. 1D).

These results demonstrate that surface type (i.e., sliced versus exterior) clearly affected the effectiveness of the CPC treatment for reducing L. monocytogenes on cooked roast beef, with the pathogen more easily reduced on exterior than on sliced surfaces. In previous works that have evaluated spray applications of CPC to RTE meats, we have observed maximum initial reductions in L. monocytogenes populations of $3.0 \mathrm{log} \mathrm{CFU} / \mathrm{g}$ on polish sausages (14) and $1.7 \log \mathrm{CFU} / \mathrm{g}$ on frankfurters (15), and we speculate that the disparity in the initial reductions achieved for these two RTE products was due, in part, to differences in surface characteristics. Other researchers have also noted the effectiveness of intervention treatments can be affected by the characteristics of the surface being treated (11).

The immediate reductions in L. monocytogenes populations observed on exterior roast beef surfaces in our study are similar in magnitude to the reductions reported by $\mathrm{Mu}-$ riana et al. (11) for thermal treatments applied either before or after packaging to the exterior of deli turkey products (reductions ranged from 2.0 to $3.8 \mathrm{log}$ ). Similarly, McCormick et al. (10) reported that thermal treatment of turkey bologna slices after packaging reduced L. monocytogenes populations by $4.5 \mathrm{log}$ immediately after treatment; after 2 months of refrigerated storage, populations on pasteurized samples remained about 4 to 5 log lower than those of controls.

Antimicrobial solutions have been evaluated for application to sliced RTE deli products for controlling L. monocytogenes. Samelis et al. (13) immersed slices of cooked pork bologna inoculated with L. monocytogenes in solu-
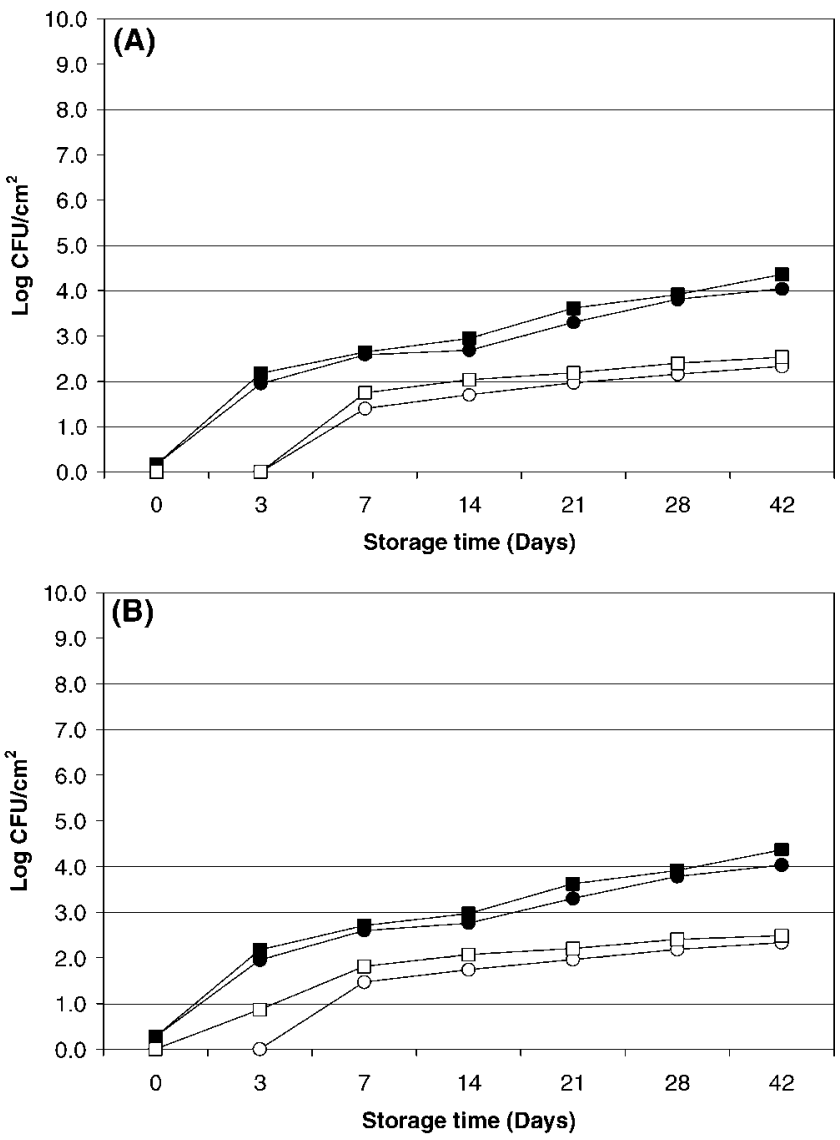

FIGURE 2. Total aerobic bacteria populations on (A) sliced and (B) exterior roast beef surfaces either not treated (control) or treated with cetylpyridinium chloride (immersion in $1 \%$ solution for $1 \mathrm{~min}$ ) and stored vacuum packaged for 42 days at 0 or $4^{\circ} \mathrm{C}$. ○, $\operatorname{Ctrl} 0^{\circ} \mathrm{C} ; \square, \operatorname{Ctrl} 4^{\circ} \mathrm{C} ; \bigcirc, \operatorname{Trt} 0^{\circ} \mathrm{C} ; \square, \operatorname{Trt} 4{ }^{\circ} \mathrm{C}$.

tions of organic acids or organic acid salts. Although the antimicrobial solutions evaluated did not appear to have significant bactericidal effects (little, if any, reduction in pathogen population immediately after treatment), pathogen outgrowth was inhibited for 120 days of refrigerated storage by acetic acid, sodium diacetate, and potassium benzoate when used at concentrations of 5\%. Subsequent evaluation of solutions containing acetic or lactic acid (3 or 5\%) combined with nisin demonstrated initial reductions in L. monocytogenes populations of about $1.5 \log$ cycles (12), which are similar in magnitude to the reductions achieved by $1 \%$ $\mathrm{CPC}$ on sliced roast beef surfaces in our current study (about $2.0 \log$ cycles).

Effect of $1 \%$ CPC treatment on naturally occurring bacterial populations. The combination of $1 \% \mathrm{CPC}$ treatment and storage days had a significant $(P=0.05)$ effect on the APCs of both sliced (Fig. 2A) and exterior (intact) (Fig. 2B) roast beef surfaces stored at 0 and $4^{\circ} \mathrm{C}$. Further analysis of main effects indicated that both storage days and $1 \% \mathrm{CPC}$ treatment had a significant $(P=0.05)$ effect on the growth of APCs at 0 and $4{ }^{\circ} \mathrm{C}$ storage temperatures for both the sliced and exterior surfaces of roast beef. The APC populations of sliced and exterior surfaces were nearly identical during the storage period. For the sliced surfaces 
TABLE 1. Lightness $\left(L^{*}\right)$, redness $\left(a^{*}\right)$, and yellowness $\left(b^{*}\right)$ values of sliced roast beef surfaces either not treated (control) or treated with cetylpyridinium chloride (immersion in $1 \%$ solution for $1 \mathrm{~min}$ ) and stored vacuum packaged for 42 days at 0 or $4^{\circ} \mathrm{C}^{a}$

\begin{tabular}{|c|c|c|c|c|c|c|}
\hline \multirow[b]{2}{*}{ Days } & \multicolumn{2}{|c|}{$\mathrm{L}^{*}$} & \multicolumn{2}{|c|}{$a^{*}$} & \multicolumn{2}{|c|}{$\mathrm{b}^{*}$} \\
\hline & Control & Treated & Control & Treated & Control & Treated \\
\hline \multicolumn{7}{|c|}{ Storage at $0^{\circ} \mathrm{C}^{b}$} \\
\hline 0 & $34.03 \pm 0.38$ & $34.28 \pm 1.41$ & $3.68 \pm 0.30$ & $3.16 \pm 0.42$ & $6.15 \pm 0.45$ & $5.01 \pm 0.83$ \\
\hline 3 & $35.58 \pm 0.55$ & $37.26 \pm 1.73$ & $3.13 \pm 0.29$ & $2.88 \pm 0.07$ & $3.96 \pm 0.51$ & $5.85 \pm 1.89$ \\
\hline 7 & $43.76 \pm 2.62$ & $41.98 \pm 3.24$ & $2.50 \pm 0.77$ & $2.06 \pm 0.38$ & $4.65 \pm 0.70$ & $4.42 \pm 0.98$ \\
\hline 14 & $37.21 \pm 1.53$ & $43.04 \pm 3.53$ & $1.70 \pm 0.18$ & $2.00 \pm 0.53$ & $4.32 \pm 0.27$ & $4.81 \pm 1.15$ \\
\hline 21 & $43.53 \pm 1.50$ & $43.05 \pm 0.54$ & $3.02 \pm 0.75$ & $2.95 \pm 0.35$ & $5.42 \pm 0.82$ & $4.62 \pm 1.33$ \\
\hline 28 & $36.14 \pm 0.65$ & $40.06 \pm 1.21$ & $1.94 \pm 0.43$ & $2.04 \pm 0.24$ & $4.04 \pm 1.32$ & $4.09 \pm 0.77$ \\
\hline 42 & $39.66 \pm 1.85$ & $40.78 \pm 1.60$ & $2.54 \pm 0.56$ & $2.03 \pm 0.39$ & $4.35 \pm 0.33$ & $3.92 \pm 0.34$ \\
\hline \multicolumn{7}{|c|}{ Storage at $4^{\circ} \mathrm{C}^{c}$} \\
\hline 0 & $31.74 \pm 3.98$ & $34.28 \pm 1.41$ & $4.36 \pm 1.21$ & $3.16 \pm 0.42$ & $7.03 \pm 1.56$ & $5.01 \pm 0.83$ \\
\hline 3 & $37.23 \pm 1.20$ & $40.72 \pm 3.72$ & $3.98 \pm 0.24$ & $2.67 \pm 1.02$ & $5.09 \pm 0.74$ & $5.27 \pm 0.86$ \\
\hline 7 & $51.45 \pm 3.66$ & $49.72 \pm 2.62$ & $4.02 \pm 0.67$ & $3.52 \pm 0.10$ & $8.69 \pm 1.79$ & $7.02 \pm 0.06$ \\
\hline 14 & $42.08 \pm 0.64$ & $46.13 \pm 5.06$ & $2.43 \pm 0.22$ & $3.48 \pm 0.95$ & $5.06 \pm 0.42$ & $7.49 \pm 2.23$ \\
\hline 21 & $43.84 \pm 3.01$ & $39.53 \pm 1.96$ & $2.66 \pm 0.51$ & $2.03 \pm 0.36$ & $4.99 \pm 1.38$ & $3.31 \pm 0.78$ \\
\hline 28 & $41.20 \pm 3.55$ & $40.69 \pm 0.38$ & $2.34 \pm 0.35$ & $2.03 \pm 0.08$ & $3.69 \pm 1.46$ & $3.29 \pm 0.21$ \\
\hline 42 & $40.95 \pm 1.32$ & $46.48 \pm 4.87$ & $2.61 \pm 0.75$ & $3.22 \pm 1.09$ & $4.81 \pm 0.98$ & $5.26 \pm 1.94$ \\
\hline
\end{tabular}

$a$ Values are means \pm standard deviations. LSD, least significant difference.

${ }^{b}$ Storage at $0^{\circ} \mathrm{C}-\mathrm{LSD}$ values for $\mathrm{L}^{*}=2.06, \mathrm{a}^{*}=0.29$, and $\mathrm{b}^{*}=0.65$.

${ }^{c}$ Storage at $4^{\circ} \mathrm{C}-\mathrm{LSD}$ values for $\mathrm{L}^{*}=1.93, \mathrm{a}^{*}=0.43$, and $\mathrm{b}^{*}=0.83$.

stored for 42 days at $4^{\circ} \mathrm{C}$, the APCs on nontreated samples reached $4.36 \log \mathrm{CFU} / \mathrm{cm}^{2}$ compared to $2.54 \log \mathrm{CFU} / \mathrm{cm}^{2}$ for treated samples (Fig. 2A). After 42 days at $0^{\circ} \mathrm{C}$, the APCs of nontreated and treated sliced surfaces were 4.04 and $2.33 \log \mathrm{CFU} / \mathrm{cm}^{2}$, respectively (Fig. 2A). For exterior roast beef surfaces stored for 42 days at $4^{\circ} \mathrm{C}$, the APCs of nontreated and treated samples were 4.37 and $2.5 \log \mathrm{CFU} /$ $\mathrm{cm}^{2}$, respectively. When stored at $0^{\circ} \mathrm{C}$ for the same time period, the APCs of nontreated and treated samples were 4.03 and $2.39 \log \mathrm{CFU} / \mathrm{cm}^{2}$, respectively (Fig. 2B). Results from this study are consistent with those reported by Cutter et al. (7), who observed reductions in APC populations on beef surfaces immediately after spray treatment with $1 \%$ $\mathrm{CPC}$ and after extended, refrigerated, vacuum-packaged storage.

Analysis of variance of LAB populations recovered from sliced and exterior surfaces of roast beef indicated that the combination of storage day and $1 \% \mathrm{CPC}$ treatment had a significant $(P=0.05)$ effect on the growth of LAB at 0 and $4{ }^{\circ} \mathrm{C}$ (data not shown). Additionally, significant $(P=$ 0.05 ) individual effects of storage day, $1 \%$ CPC treatment, and storage temperature were observed for sliced surfaces. Storage temperature $\left(0\right.$ and $\left.4^{\circ} \mathrm{C}\right)$ did not have a significant $(P>0.05)$ effect on the growth of LAB on the exterior surfaces of roast beef. After 42 days of storage, LAB populations on nontreated sliced surfaces stored at 0 and $4^{\circ} \mathrm{C}$ were 3.41 and $3.83 \log \mathrm{CFU} / \mathrm{cm}^{2}$, respectively, while $\mathrm{LAB}$ populations on treated samples stored at 0 and $4^{\circ} \mathrm{C}$ were 2.01 and $2.17 \log \mathrm{CFU} / \mathrm{cm}^{2}$, respectively (data not shown). For exterior surfaces, treatment with $1 \% \mathrm{CPC}$ held $\mathrm{LAB}$ populations to 2.10 and $2.27 \mathrm{log} \mathrm{CFU} / \mathrm{cm}^{2}$ after 42 days of storage at 0 and $4^{\circ} \mathrm{C}$, respectively, compared to 3.39 and
$3.82 \log \mathrm{CFU} / \mathrm{cm}^{2}$ for nontreated (control) surfaces stored at 0 and $4^{\circ} \mathrm{C}$, respectively.

For all samples (treated and nontreated), yeast and mold, total coliform, and E. coli populations were below detectable limits $\left(<0.75 \mathrm{CFU} / \mathrm{cm}^{2}\right)$ on both sliced and exterior roast beef surfaces on all sampling days and at all storage temperatures.

Effect of 1\% CPC treatment on color of roast beef. Tables 1 and 2 summarize the influence of $1 \%$ CPC treatment, storage temperature, and storage time on the color of sliced and exterior roast beef surfaces stored at 0 and $4^{\circ} \mathrm{C}$. Although statistically significant $(P=0.05)$ differences were observed among lightness $\left(\mathrm{L}^{*}\right)$, redness $\left(\mathrm{a}^{*}\right)$, and yellowness $\left(b^{*}\right)$ values of various samples, these differences could be due in part to the restructured nature of the roast beef product, possibly resulting in interference of the fat pockets (observed visually on the product) at the time of color analysis.

For sliced surfaces stored at $0^{\circ} \mathrm{C}$, no significant $(P>$ $0.05)$ differences were observed in the $\mathrm{L}^{*}$ values of nontreated ( $\mathrm{L}^{*}$ values ranging from 34.03 to 43.76 ) and $1 \%$ CPC-treated samples ( $\mathrm{L}^{*}$ values ranging from 34.28 to 43.05) (Table 1). Storage time had a significant $(P=0.05)$ effect on the $L^{*}$ values of exterior roast beef surfaces irrespective of $1 \% \mathrm{CPC}$ treatment and storage temperature (Table 2). Significant $(P=0.05)$ differences were observed for the interactive effects of temperature and storage days, as well as for the treatment and storage days, on the $a^{*}$ values of sliced roast beef surfaces (Table 1). Storage time and $1 \% \mathrm{CPC}$ treatment had a significant $(P=0.05)$ effect on the $\mathrm{a}^{*}$ values of exterior surfaces stored at 0 and $4^{\circ} \mathrm{C}$ (Table 2). Significant $(P=0.05)$ effects of (i) treatment 
TABLE 2. Lightness $\left(L^{*}\right)$, redness $\left(a^{*}\right)$, and yellowness $\left(b^{*}\right)$ values of exterior roast beef surfaces either not treated (control) or treated with cetylpyridinium chloride (immersion in $1 \%$ solution for $1 \mathrm{~min}$ ) and stored vacuum packaged for 42 days at 0 or $4^{\circ} \mathrm{C}^{a}$

\begin{tabular}{|c|c|c|c|c|c|c|}
\hline \multirow[b]{2}{*}{ Days } & \multicolumn{2}{|c|}{$\mathrm{L}^{*}$} & \multicolumn{2}{|c|}{$a^{*}$} & \multicolumn{2}{|c|}{$\mathrm{b}^{*}$} \\
\hline & Control & Treated & Control & Treated & Control & Treated \\
\hline \multicolumn{7}{|c|}{ Storage at $0^{\circ} \mathrm{C}^{b}$} \\
\hline 0 & $34.03 \pm 0.38$ & $32.27 \pm 4.14$ & $3.68 \pm 0.30$ & $2.72 \pm 0.30$ & $6.15 \pm 0.45$ & $6.79 \pm 0.50$ \\
\hline 3 & $36.90 \pm 1.18$ & $36.54 \pm 0.00$ & $3.26 \pm 0.36$ & $1.99 \pm 0.00$ & $5.35 \pm 1.38$ & $5.48 \pm 0.00$ \\
\hline 7 & $46.24 \pm 7.48$ & $44.51 \pm 5.73$ & $2.72 \pm 1.91$ & $2.32 \pm 1.50$ & $5.11 \pm 2.46$ & $4.91 \pm 0.45$ \\
\hline 14 & $39.91 \pm 1.25$ & $41.47 \pm 3.14$ & $2.04 \pm 0.57$ & $1.87 \pm 0.50$ & $5.86 \pm 0.38$ & $5.85 \pm 2.14$ \\
\hline 21 & $43.73 \pm 3.14$ & $42.96 \pm 4.52$ & $2.53 \pm 0.44$ & $2.72 \pm 1.10$ & $4.90 \pm 1.12$ & $4.42 \pm 2.57$ \\
\hline 28 & $41.23 \pm 0.91$ & $36.75 \pm 3.80$ & $2.13 \pm 0.15$ & $1.64 \pm 0.32$ & $5.24 \pm 0.59$ & $4.94 \pm 0.75$ \\
\hline 42 & $41.89 \pm 5.01$ & $41.25 \pm 0.61$ & $2.30 \pm 0.49$ & $1.80 \pm 0.26$ & $6.22 \pm 0.94$ & $4.94 \pm 1.79$ \\
\hline \multicolumn{7}{|c|}{ Storage at $4^{\circ} \mathrm{C}^{c}$} \\
\hline 0 & $31.91 \pm 1.01$ & $32.27 \pm 4.14$ & $2.96 \pm 0.34$ & $2.72 \pm 0.30$ & $6.98 \pm 0.27$ & $6.79 \pm 0.50$ \\
\hline 3 & $40.30 \pm 2.91$ & $42.52 \pm 0.99$ & $3.55 \pm 1.22$ & $2.06 \pm 0.07$ & $6.27 \pm 0.58$ & $6.23 \pm 0.61$ \\
\hline 7 & $43.56 \pm 6.65$ & $53.42 \pm 3.65$ & $2.55 \pm 0.42$ & $3.59 \pm 0.40$ & $6.89 \pm 0.62$ & $9.35 \pm 0.69$ \\
\hline 14 & $39.21 \pm 1.10$ & $41.44 \pm 4.35$ & $2.76 \pm 1.15$ & $2.01 \pm 0.74$ & $6.48 \pm 3.15$ & $5.25 \pm 1.76$ \\
\hline 21 & $38.56 \pm 3.22$ & $37.60 \pm 2.20$ & $2.48 \pm 1.36$ & $1.41 \pm 0.55$ & $4.67 \pm 4.10$ & $2.35 \pm 1.36$ \\
\hline 28 & $38.22 \pm 0.19$ & $39.19 \pm 2.96$ & $1.75 \pm 0.19$ & $1.63 \pm 0.38$ & $3.15 \pm 0.35$ & $4.34 \pm 0.55$ \\
\hline 42 & $43.18 \pm 2.64$ & $40.57 \pm 0.77$ & $2.63 \pm 0.49$ & $2.50 \pm 0.49$ & $5.33 \pm 1.39$ & $5.41 \pm 1.90$ \\
\hline
\end{tabular}

$a$ Values are means \pm standard deviations. LSD, least significant difference.

${ }^{b}$ Storage of $0^{\circ} \mathrm{C}-\mathrm{LSD}$ values for $\mathrm{L}^{*}=2.33$, $\mathrm{a}^{*}=0.50$, and $\mathrm{b}^{*}=0.86$.

${ }^{c}$ Storage at $4^{\circ} \mathrm{C}-\mathrm{LSD}$ values for $\mathrm{L}^{*}=2.02, \mathrm{a}^{*}=0.41$, and $\mathrm{b}^{*}=1.13$.

and storage day and (ii) storage temperature and storage day on the $b^{*}$ values of sliced roast beef surfaces were observed. The $b^{*}$ values of sliced roast beef surfaces increased when samples were treated with $1 \% \mathrm{CPC}$ and stored at $4^{\circ} \mathrm{C}$ for 42 days (Table 1 ). For exterior roast beef surfaces, a significant $(P=0.05)$ effect of storage day on the $b^{*}$ values, irrespective of storage temperature and $1 \%$ CPC treatment, was observed (Table 2). The yellowness of exterior roast beef surfaces treated with $1 \% \mathrm{CPC}$ and stored at $4^{\circ} \mathrm{C}$ fluctuated for 42 days.

TABLE 3. Firmness values of sliced and exterior roast beef surfaces either not treated (control) or treated with cetylpyridinium chloride (immersion in $1 \%$ solution for $1 \mathrm{~min}$ ) and stored vaccuum packaged for 42 days at 0 or $4^{\circ} \mathrm{C}^{a}$

Firmness (g)

$0^{\circ} \mathrm{C}$

$4^{\circ} \mathrm{C}$

Days Control Treated Control Treated

Sliced/cut surfaces ${ }^{b}$

$\begin{array}{rr}0 & 17,030.7 \pm 525.75 \\ 3 & 18,245.23 \pm 971.48 \\ 7 & 16,815.74 \pm 438.76 \\ 14 & 14,902.63 \pm 378.78 \\ 21 & 15,432.63 \pm 584.58 \\ 28 & 16,709.45 \pm 343.63 \\ 42 & 16,934.47 \pm 661.86\end{array}$

$$
\begin{aligned}
& 13,710.55 \pm 276.64 \\
& 15,651.87 \pm 774.40 \\
& 15,308.89 \pm 372.26 \\
& 14,446.25 \pm 111.62 \\
& 14,157.36 \pm 435.34 \\
& 11,450.43 \pm 409.58 \\
& 16,014.47 \pm 271.94
\end{aligned}
$$

$12,080.55 \pm 226.06$
$12,666.72 \pm 879.23$
$11,696.20 \pm 328.95$
$13,312.94 \pm 659.64$
$12,682.64 \pm 701.27$
$11,459.04 \pm 14.01$
$13,015.43 \pm 52.86$

$15,422.34 \pm 1,820.90$
$14,998.58 \pm 616.15$
$14,814.49 \pm 1,060.91$
$14,458.34 \pm 82.05$
$16,275.06 \pm 270.68$
$16,794.49 \pm 434.43$
$19,674.87 \pm 4,166.56$

$14,582.31 \pm 1,166.09$

$15,913.27 \pm 866.43$

$17,970.13 \pm 1,999.76$

$16,610.16 \pm 1,093.46$

$13,245.89 \pm 75.32$

$15,899.57 \pm 193.56$

$12,688.40 \pm 1,684.07$

Exterior surfaces ${ }^{c}$

$\begin{array}{rl}0 & 15,979.45 \pm 334.59 \\ 3 & 15,609.76 \pm 1,015.49 \\ 7 & 14,379.51 \pm 522.04 \\ 14 & 14,900.73 \pm 629.75 \\ 21 & 15,359.48 \pm 1,186.72 \\ 28 & 15,866.04 \pm 1,121.34 \\ 42 & 14,908.72 \pm 900.61\end{array}$

${ }^{a}$ Values are means \pm standard deviations. LSD, least significant difference.

${ }^{b}$ Sliced surfaces-within sampling day (row), LSD $=714.67$; within storage temperature $\times$ treatment combination $($ column), LSD $=$ 1,344 .

${ }^{c}$ Exterior surfaces-within sampling day (row), LSD $=433.72$; within storage temperature $\times$ treatment combination $($ column), LSD $=813.43$. 


\section{Effect of 1\% CPC treatment on firmness of roast}

beef. As noted previously, the restructured nature of the roast beef product may have partially contributed to differences in firmness values. Significant differences $(P=0.05)$ were observed in the firmness of sliced roast beef surfaces stored for 42 days at 0 and $4^{\circ} \mathrm{C}$ (Table 3). A significant $(P$ $=0.05$ ) interactive effect of storage temperature and $1 \%$ CPC treatment was observed on the firmness of exterior roast beef surfaces (Table 3 ). Storage temperatures ( 0 and $\left.4^{\circ} \mathrm{C}\right)$ had a significant $(P=0.05)$ effect on the firmness of nontreated and treated sliced roast beef surfaces. The firmness of nontreated (control) samples was consistently higher than that of 1\% CPC-treated samples (Table 3). An unusual increase in the firmness of nontreated (control) sliced surfaces was observed on day 42 at $4^{\circ} \mathrm{C}$. For exterior roast beef surfaces, CPC-treated samples stored at $0^{\circ} \mathrm{C}$ were consistently less firm than CPC-treated samples stored at $4^{\circ} \mathrm{C}$ and were also consistently less firm than nontreated samples (Table 3).

Our experimental results demonstrate that $1 \% \mathrm{CPC}$ treatment can reduce L. monocytogenes contamination on RTE deli products, such as roast beef. Immediately after treatment, a nearly $2-\log \mathrm{CFU} / \mathrm{cm}^{2}$ reduction in L. monocytogenes populations was achieved on sliced roast beef surfaces, and a reduction of ca. $4 \log \mathrm{CFU} / \mathrm{cm}^{2}$ was achieved on exterior surfaces. This suggests that the application of CPC treatments to deli products prior to slicing maximizes beneficial antimicrobial effects while also minimizing any effects on product quality. Areas warranting further evaluation include the impacts of CPC treatment on sensory characteristics (e.g., taste), which is most appropriately evaluated on a product-by-product basis, as well as the efficacy of CPC for controlling the outgrowth of $L$. monocytogenes when RTE products are stored at "abusive" temperatures.

\section{ACKNOWLEDGMENTS}

Support was provided by the Cooperative State Research, Extension and Education Service, USDA, under agreement no. 2003-34211-12998, Food Safety Consortium. This work was also supported in part by the American Meat Institute Foundation.

\section{REFERENCES}

1. Aymerich, T., A. Jofre, M. Garriga, and M. Hugas. 2005. Inhibition of Listeria monocytogenes and Salmonella by natural antimicrobials and high hydrostatic pressure in sliced cooked ham. J. Food Prot. 68:173-177.

2. Breen, P. J., C. M. Compadre, E. K. Fifer, H. Salari, D. C. Serbus, and D. L. Lattin. 1995. Quaternary ammonium compounds inhibit and reduce the attachment of viable Salmonella typhimurium to poultry tissues. J. Food Sci. 60:1191-1196.

3. Breen, P. J., H. Salari, and C. M. Compadre. 1997. Elimination of Salmonella contamination from poultry tissues by cetylpyridinium chloride solutions. J. Food Prot. 60:1019-1021.

4. Cagri, A., Z. Ustunol, and E. T. Ryser. 2002. Inhibition of three pathogens on bologna and summer sausage using antimicrobial edible films. J. Food Sci. 67:2317-2324.

5. Centers for Disease Control and Prevention. 2002. Public health dispatch: outbreak of Listeriosis-northeastern United States, 2002. Morb. Mortal. Wkly. Rep. 51:950-951.

6. Centers for Disease Control and Prevention. 2003. Disease information-Listeriosis. CDC Division of Bacterial and Mycotic Diseases. Available at: http://www.cdc.gov/ncidod/dbmd/diseaseinfo/listeriosis_t.htm. Accessed 7 October 2004
7. Cutter, C. N., W. J. Dorsa, A. Handie, S. Rodriguez-Morales, X. Zhou, P. J. Breen, and C. M. Compadre. 2000. Antimicrobial activity of cetylpyridinium chloride washes against pathogenic bacteria on beef surfaces. J. Food Prot. 63:593-600.

8. Farber, J. M., and P. I. Peterkin. 1991. Listeria monocytogenes, a food-borne pathogen. Microbiol. Rev. 55:476-511.

9. Levine, P., B. Rose, S. Green, G. Ransom, and W. Hill. 2001. Pathogen testing of ready-to-eat meat and poultry products collected at federally inspected establishments in the United States, 1990 to 1999. J. Food Prot. 64:1188-1193.

10. McCormick, K. E., I. Y. Han, J. C. Acton, B. W. Sheldon, and P. L. Dawson. 2005. In-package pasteurization combined with biocideimpregnated films to inhibit Listeria monocytogenes and Salmonella Typhimurium in turkey bologna. J. Food Sci. 70:M52-M57.

11. Muriana, P., N. Gande, W. Robertson, B. Jordan, and S. Mitra. 2004. Effect of prepackage and postpackage pasteurization on postprocess elimination of Listeria monocytogenes on deli turkey products. $J$. Food Prot. 67:2472-2479.

12. Samelis, J., G. K. Bedie, J. N. Sofos, K. E. Belk, J. A. Scanga, and G. C. Smith. 2005. Combinations of nisin with organic acids or salts to control Listeria monocytogenes on sliced pork bologna stored at $4^{\circ} \mathrm{C}$ in vacuum packages. Lebensm.-Wiss. Technol. 38:21-28.

13. Samelis, J., J. N. Sofos, M. L. Kain, J. A. Scanga, K. E. Belk, and G. C. Smith. 2001. Organic acids and their salts as dipping solutions to control Listeria monocytogenes inoculated following processing of sliced pork bologna stored at $4^{\circ} \mathrm{C}$ in vacuum packages. J. Food Prot. 64:1722-1729.

14. Singh, M., V. S. Gill, H. Thippareddi, R. K. Phebus, J. L. Marsden, T. J. Herald, and A. L. Nutsch. Cetylpyridinium chloride treatment of ready-to-eat polish sausages: effects on Listeria monocytogenes populations and quality attributes. Foodborne Pathogens Dis., in press.

15. Singh, M., V. S. Gill, H. Thippareddi, R. K. Phebus, J. L. Marsden, T. J. Herald, and A. L. Nutsch. Antimicrobial activity of cetylpyridinium chloride against Listeria monocytogenes on frankfurters and subsequent effect on quality attributes. J. Food Prot. 68:1823-1830.

16. U.S. Food and Drug Administration. 2004. Final rule: secondary direct food additives permitted in food for human consumption. Fed. Regist. 69:17297-17298.

17. U.S. Food and Drug Administration, Center for Food Safety and Applied Nutrition. 2003. Quantitative assessment of the relative risk to public health from foodborne Listeria monocytogenes among selected categories of ready-to-eat foods. Available at: http:// www.cfsan.fda.gov/ dms/lmr2-toc.html. Accessed 15 December 2004.

18. U.S. Department of Agriculture, Food Safety and Inspection Service. 2002. Directive 10,240.3. Microbial sampling of ready-to-eat (RTE) products for the FSIS verification testing program. Available at: http://www.fsis.usda.gov/OPPDE/rdad/FSISDirectives/10240.3.pdf. Accessed 15 December 2004.

19. U.S. Department of Agriculture, Food Safety and Inspection Service. 2003. Control of Listeria monocytogenes in ready-to-eat meat and poultry products; interim final rule. Fed. Regist. 68:34208-34254.

20. U.S. Department of Agriculture, Food Safety and Inspection Service. 2004. FSIS Directive 7120.1, amendment 2 - safe and suitable ingredients used in the production of meat and poultry products. Available at: http://fsis.usda.gov/OPPDE/rdad/FSISDirectives/7120.1Amend2.pdf. Accessed 15 December 2004.

21. Wang, H., Y. B. Li, and M. F. Slavik. 2001. Efficacy of cetylpyridinium chloride in immersion treatment for reducing populations of pathogenic bacteria on fresh-cut vegetables. J. Food Prot. 64:20712074.

22. Wang, W. C., Y. Li, M. F. Slavik, and H. Xiong. 1997. Trisodium phosphate and cetylpyridinium chloride spraying on chicken skin to reduce attached Salmonella typhimurium. J. Food Prot. 60:992-994.

23. Xiong, H., Y. Li, M. F. Slavik, and T. J. Walker. 1998. Spraying chicken with selected chemicals to reduce attached Salmonella typhimurium. J. Food Prot. 61:272-275.

24. Zaika, L. L., S. L. Palumbo, J. L. Smith, F. D. Corral, S. Bhaduri, C. O. Jones, and A. H. Kim. 1990. Destruction of Listeria monocytogenes during frankfurter processing. J. Food Prot. 53:18-21. 